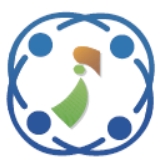

\title{
Robust Sliding Mode Control based MPPT for a PV/Wind Hybrid Energy System
}

\author{
Otmane Zebraoui $^{1 *} \quad$ Mostafa Bouzi $^{1}$ \\ ${ }^{1}$ Laboratory of Engineering, Industrial Management and Innovation Faculty of Sciences and Technology, \\ Hassan First University, Morocco \\ * Corresponding author’s Email: otmanezebraoui@gmail.com
}

\begin{abstract}
In this paper, we present a modeling and simulation study of a hybrid energy system for isolated sites, which combines photovoltaic system with wind turbine based on permanent magnet synchronous generator (PMSG). With the aim of improving the performances and extracting the maximum energy produced by the two Photovoltaic (PV) and Wind sources, we developed a maximum power point tracking (MPPT) controller with robust algorithms based on the nonlinear sliding mode control (SMC). Thus, other conventional MPPT methods have been simulated and evaluated to compare them with the proposed algorithms in order to deduce the most efficient in terms of the maximum power reach and the system behavior during optimal power point tracking. And for a better analysis study, the simulations are carried out under variable weather conditions. The simulation results show that the proposed robust sliding mode control techniques (RSMC) are more efficient and have better performance than other MPPT algorithms.
\end{abstract}

Keywords: Hybrid energy system, MPPT, Sliding mode control (SMC), Wind system, Photovoltaic system, PMSG.

\section{Introduction}

Currently, one of the proposed technological solutions for isolated sites electrification, and therefore solve the problems of using classical techniques to ensure a power grid extension, as well as the environmental and economic disadvantages of using fossil energy sources, we find the use of socalled hybrid energy production systems, which combines renewable energy sources such as solar and wind, which allows ensuring the supply security and autonomy in energy whatever the weather conditions, what has a considerable advantage compared to other systems based on a single energy source [1]. With the aim of a better exploitation of these hybrid systems, using an MPPT controller is required to operate both $\mathrm{PV}$ and Wind sources in their maximum power point (MPP) at any time and regardless of the climatic conditions [2], which improves their energy performance and consequently optimizes the performance of $\mathrm{PV} /$ Wind complete system. In the literature, there are several proposed MPPT algorithms to control both PV and Wind energy systems [3, 4].

Our main objective is to study the modeling, control and optimization of a hybrid energy system for isolated and remote sites, system includes a PV generator, a permanent magnet synchronous generator (PMSG), a storage system (batteries) and the assembly supplies a dc electrical load. as well as proposing new MPPT approaches for both PV and Wind systems, and developing an intelligent energy management strategy of the full hybrid system.

In this work, we present a part of our study which consists, on the one hand, the modeling and the simulation of a hybrid energy system combines two energy production chains; a PV system [5] that consists of a photovoltaic generator and a $\mathrm{dc} / \mathrm{dc}$ booster converter, a Wind system [6] consists of a wind turbine, a PMSG generator, a ac/dc rectifier and a dc/dc boost converter. And on the other hand, optimize and improve the proposed system performance, by developing a robust MPPT controller based on the nonlinear sliding mode 
control [7]. A controller based on two robust sliding mode control (RSMC) algorithms that allow extracting the maximum power from both PV and Wind systems whatever the climate changes, irradiation, temperature and wind speed. These algorithms are based on the nonlinear sliding mode control due to its excellent advantages, such as the great robustness under external parameters variation, climate change in our case, the best dynamic response to find the maximum power point (MPP), high accuracy and good stability of the system around the MPP and its implementation simplicity. The only disadvantage of this command is the presence of chattering. Generally, sliding mode control based on two elements to be defined: the sliding surface and equivalent control. Our aim in this work is to improve more: the system dynamic response time, the accuracy and stability with high efficiency, reduce the chattering phenomenon and oscillations around the MPP to minimize energy losses. For that, we have proposed robust algorithms based on reference parameters that are calculated and subsequently used to determine the sliding surface and equivalent control and consequently improve the efficiency of sliding mode control application in a nonlinear system. The proposed algorithm for PV system is based on the use of a reference voltage defined by perturb and observe algorithm $(\mathrm{P} \& \mathrm{O})$ in the sliding mode technique to define the control law. For wind system, the proposed algorithm is based on a reference current calculated from the wind turbine reference parameters.

Thus, other traditional MPPT methods are realized and simulated in order to analyze and compare them with the proposed algorithms, namely, Perturb and Observe (P\&O) [3, 5, 7] and Incremental Conductance (INC) [3] for PV system and Hill Climbing Search (HCS) [4] for Wind system.

The system simulation study and results analysis confirm that the proposed controller can improve the system performance and achieve the desired objectives with significant advantages in terms of energy efficiency, good system behavior to reach and follow the optimal power point with better response time, good accuracy and less oscillation.

After this introduction, the rest of the paper is structured as follows: in section 2 , we introduce a detailed description and modeling of the proposed PV/Wind hybrid system. In section 3, the different classical MPPT methods used to optimize the PV and Wind systems with also the proposed robust sliding mode control algorithms (RSMC) are described. The simulation results and discussion of the MPPT techniques performances on our system are presented in section 4. Finally, conclusions of this work with our perspectives in the future works are given in section 5 .

\section{Hybrid energy system: Description and modeling}

The architecture of the proposed hybrid energy system is presented in Fig. 1, it consists of two renewable energy production subsystems, PV and Wind, connected in parallel to a dc bus line which supplies a dc electrical load, with the use of an MPPT controller which allows to optimize and maximize the power produced by both PV and Wind systems. The Photovoltaic (PV) system [2] contains a PV array and $\mathrm{dc} / \mathrm{dc}$ boost converter. The wind system [4] based on a wind turbine coupled with a permanent magnet synchronous generator (PMSG), $\mathrm{ac} / \mathrm{dc}$ diode rectifier and $\mathrm{dc} / \mathrm{dc}$ boost converter for the output power conversion and regulation.

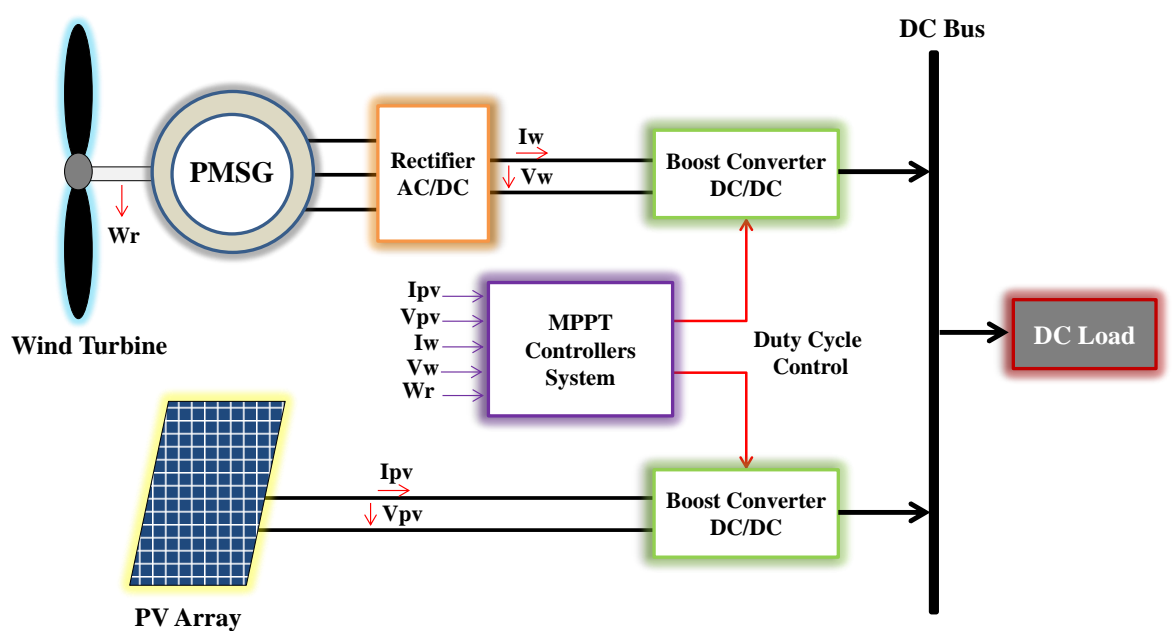

Figure.1 Hybrid energy system architecture 


\subsection{Modeling of wind system}

The wind energy conversion system studied [4] [6] consists mainly of a wind turbine coupled to a permanent magnet synchronous generator (PMSG) [8] which is characterized by its high reliability, requires less maintenance, no need for gearbox and more efficiency, a ac/dc inverter and a dc/dc boost converter. The turbine converts the kinetic energy of the wind into mechanical power, the generator converts mechanical energy into electrical energy, then the rectifier converts this ac voltage to dc voltage and supplies the $\mathrm{dc} / \mathrm{dc}$ boost converter which allows using an MPPT control to reach and track the maximum power point produced by the generator. In general, a wind system characterized essentially by: the mechanical power $P_{m}$, the mechanical torque $T_{m}$ and the tip speed ratio (TSR).

The mechanical power $P_{m}$ generated by the wind turbine can be expressed by [6]:

$P_{m}=\frac{1}{2} \rho S C_{p}(\lambda, \beta) V_{\text {wind }}^{3}$

Where: $\rho$ is the air density $\left(\mathrm{Kg} / \mathrm{m}^{3}\right), S$ is the swept area of turbine, $V_{\text {wind }}$ is the wind speed $(\mathrm{m} / \mathrm{s})$, and $C_{p}$ is the turbine power coefficient given by [2]:

$C_{p}(\lambda, \beta)=C_{1}\left(C_{2} \frac{1}{\lambda_{i}}-C_{3} \beta-C_{4}\right) e^{\frac{-C_{5}}{\lambda_{i}}}+C_{6} \lambda$

Where: $\lambda$ is the tip speed ratio of the rotor blades, $\beta$ is the blade pitch angle, $C_{1}=0.5176, C_{2}=116$, $C_{3}=0.4, C_{4}=5, C_{5}=21, C_{6}=0.0068$ are the values of the coefficients $C_{1}$ to $C_{6}$ respectively and $\lambda_{i}$ is defined by [2]:

$\frac{1}{\lambda_{i}}=\frac{1}{\lambda+0.08 \beta}-\frac{0.035}{\beta^{3}+1}$

The tip speed ratio of the wind turbine is defined as:

$\lambda=\frac{\omega_{r} R}{V_{\text {wind }}}$

Where, $R$ is the wind turbine rotor radius in meters $(\mathrm{m})$ and $\omega_{r}$ is the wind turbine rotor speed.

The mechanical torque $T_{m}$ of the wind turbine is expressed by the equation:

$T_{m}=\frac{P_{m}}{\omega_{r}}$

Table 1 shows the technical parameters of the wind turbine and the permanent magnet synchronous generator (PMSG) used in this study:
Table 1. Parameters of wind turbine and PMSG

\begin{tabular}{l|l}
\hline \multicolumn{2}{c}{ The Wind turbine } \\
\hline Parameter & Values \\
\hline Nominal Mechanical Output Power & $8.5 \mathrm{~kW}$ \\
Base Wind Speed & $12 \mathrm{~m} / \mathrm{s}$ \\
Air Density $\boldsymbol{\rho}$ & $1.225 \mathrm{~kg} / \mathrm{m}^{3}$ \\
Pitch Angle $\boldsymbol{\beta}$ & $0^{\circ}$ \\
\hline \multicolumn{2}{|c}{ PMSG Generator } \\
\hline Parameter & Values \\
\hline Number of Pole Pairs & 5 \\
Stator Phase Resistance & $0.425 \Omega$ \\
Armature Inductance & $0.000835 \mathrm{H}$ \\
Friction Factor & $0.001189 \mathrm{Nms}$ \\
Inertia constant & $0.01197 \mathrm{~kg} \cdot \mathrm{m}^{2}$ \\
\hline
\end{tabular}

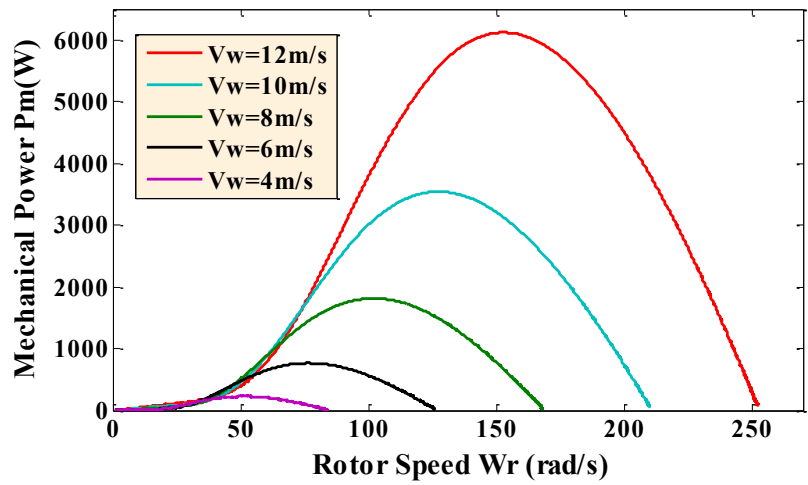

Figure. $2 \mathrm{P}_{\mathrm{m}}\left(\mathrm{V}_{\text {wind }}\right)$ mechanical power of the wind turbine for various values of wind speed

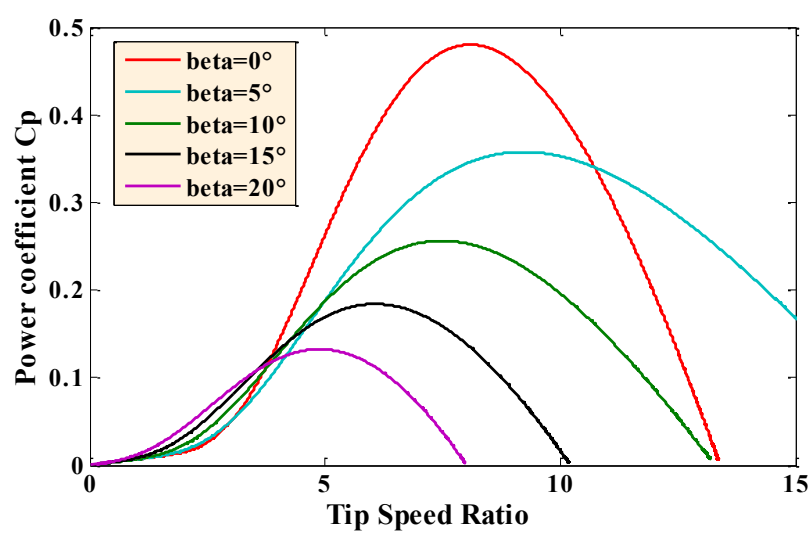

Figure.3 Power coefficient for the various pitch angle values $\beta$

Fig. 2 shows the mechanical power of the wind turbine as a function of the rotor speed $P_{m}\left(\omega_{r}\right)$ for different wind speed values. Fig. 3 shows the power coefficient as a function of the tip speed ratio $C_{p}(\lambda)$ for various pitch angle values $\beta$, Its optimal value occurs at $\beta=0$ and at the tip speed ratio optimal value $\left(\lambda_{\text {opt }}=8.144\right)$, which equal to 0.48 .

According to these characteristic curves $P_{m}\left(\omega_{r}\right)$ and $C_{p}(\lambda)$, it is noted that for each wind speed there is an operating point where the mechanical power and the power coefficient are optimal. However, the 
use of an MPPT controller is essential to reach and track this maximum power point whatever the wind speed values.

\subsection{Modeling of PV system}

A photovoltaic panel includes several parallel PV modules composed of solar cells connected in series. The PV cell consists of a p-n semiconductor junction that converts solar irradiation into electrical energy. Fig. 4 shows the equivalent circuit of PV cell $[7,9,10]$ which based on a current source in parallel with one diode, a series resistance and a shunt resistance:

Using this equivalent circuit, the current-voltage I-V characteristic of this PV array can be expressed by the following equation [3]:

$$
\begin{aligned}
I_{p v}= & N_{p} I_{p h}-N_{p} I_{0}\left[\exp \left(\frac{q\left(V_{p v}+\left(N_{S} / N_{p}\right) R_{s} I_{p v}\right)}{N_{S} A K T}\right)-1\right]- \\
& \frac{V_{p v}+\left(N_{S} / N_{p}\right) R_{s} I_{p v}}{\left(N_{S} / N_{p}\right) R_{s h}}
\end{aligned}
$$

Where: $I_{p v}$ and $V_{p v}$ are the PV generator output current and voltage, $I_{p h}$ is the PV cell photo-current (A), $I_{o}$ is the reverse saturation current (A), $N_{s}$ and $N_{p}$ are the number of series cell and the parallel modules respectively, $R_{s}$ and $R_{s h}$ is the series and the shunt resistance respectively, $q$ is the electron charge $\left(1.602 * 10^{-19} \mathrm{C}\right), A$ is the diode ideality factor, $K$ is the Boltzmann constant $\left(1,38^{*} 10^{-23} \mathrm{~J} / \mathrm{K}\right)$ and $T$ is the junction temperature in Kelvin (k).

The PV cell photo-current $I_{p h}$ and the reverse saturation current $I_{o}$ are given by:

$$
\begin{aligned}
& I_{p h}=\left[I_{s c}+K_{i}\left(T-T_{r e f}\right)\right] \frac{G}{G_{r e f}} \\
& I_{0}=I_{r s}\left(\frac{T}{T_{r e f}}\right)^{3} \exp \left[\frac{q E_{g}}{A K}\left(\frac{1}{T_{r e f}}-\frac{1}{T}\right)\right]
\end{aligned}
$$

Where: $I_{s c}$ is the short-circuit current at reference conditions, $K_{i}$ is the short circuit current temperature coefficient, $E_{g}$ is the band-gap energy of the PV cell semiconductor and $I_{r s}$ is the saturation current at the reference temperature. With the reference conditions are: $G_{r e f}\left(1000 \mathrm{~W} / \mathrm{m}^{2}\right)$ and $T_{r e f}\left(25^{\circ} \mathrm{C}\right)$.

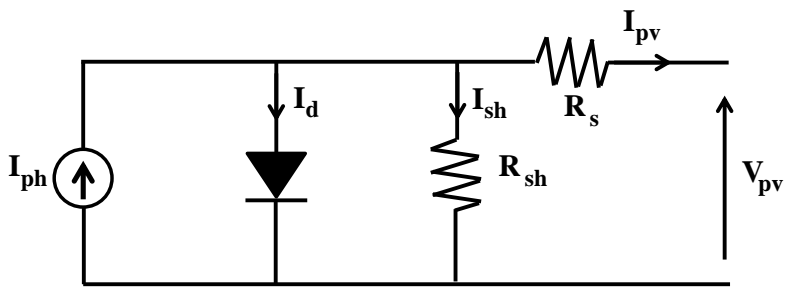

Figure.4 Equivalent circuit of PV cell
In this work, we used the PV module sharp ND240QCJ characterized by the technical parameters listed in the following table:

Table 2. Electrical parameters of ND-240QCJ PV Module

\begin{tabular}{l|l}
\hline Parameter & Values \\
\hline Maximum power at $\mathrm{STC}\left(\mathrm{P}_{\max }\right)$ & $240 \mathrm{~W}$ \\
Cell serial modules $\left(\mathrm{N}_{\mathrm{s}}\right)$ & 60 \\
Open Circuit Voltage $\left(\mathrm{V}_{\mathrm{oc}}\right)$ & $37.5 \mathrm{~V}$ \\
Maximum Power Voltage $\left(\mathrm{V}_{\mathrm{pm}}\right)$ & $29.3 \mathrm{~V}$ \\
Short Circuit Current $\left(\mathrm{I}_{\mathrm{sc}}\right)$ & $8.75 \mathrm{~A}$ \\
Maximum Power Current $\left(\mathrm{I}_{\mathrm{pm}}\right)$ & $8.19 \mathrm{~A}$ \\
Temperature Coefficient $\left(\mathrm{l}_{\mathrm{sc}}\right) \mathrm{K}_{\mathrm{i}}$ & $0.053 \% /{ }^{\circ} \mathrm{C}$ \\
Temperature Coefficient $\left(\mathrm{V}_{\mathrm{oc}}\right) \mathrm{K}_{\mathrm{v}}$ & $-0.36 \% /{ }^{\circ} \mathrm{C}$ \\
\hline
\end{tabular}

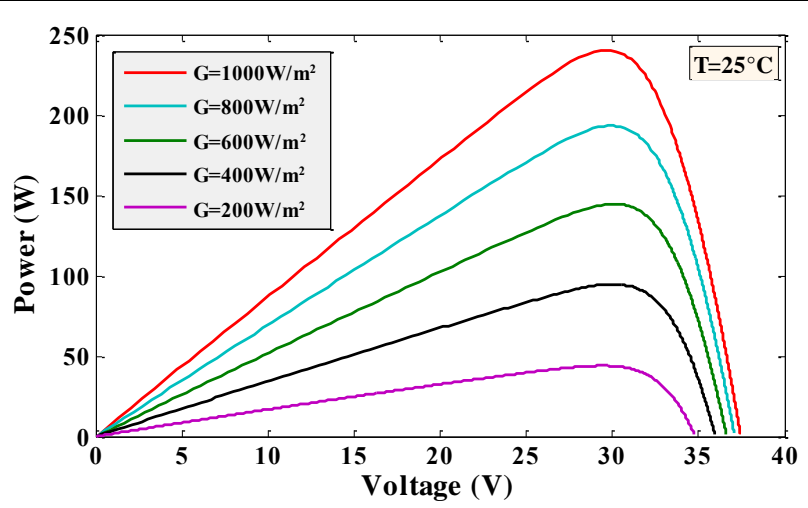

Figure.5 P-V characteristics of a PV module for various irradiance values at a temperature of $25^{\circ} \mathrm{C}$

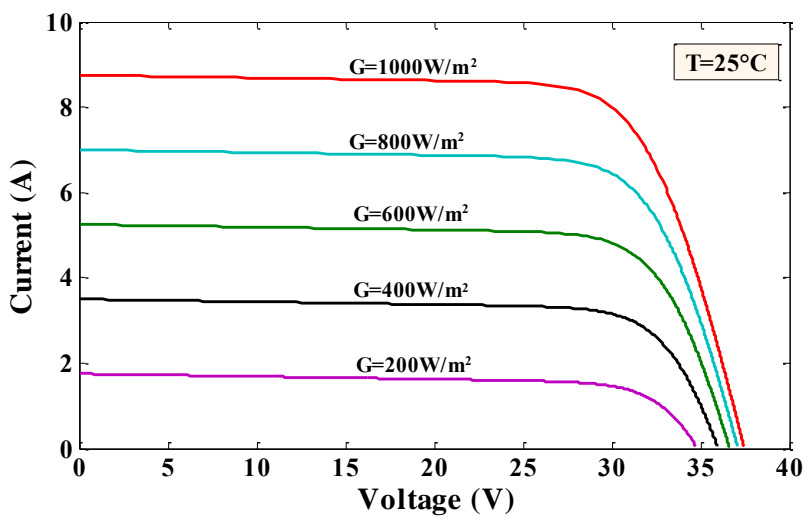

Figure.6 I-V characteristics of a PV module for various irradiance values at a temperature of $25^{\circ} \mathrm{C}$

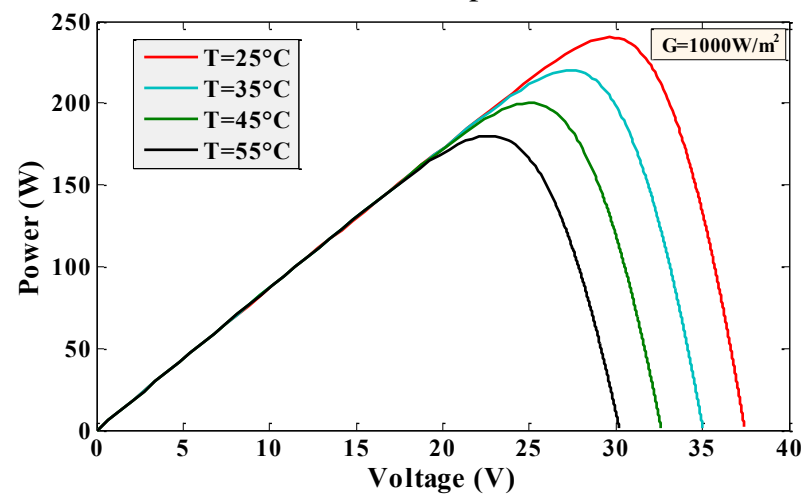

Figure.7 P-V characteristics of a PV module for various temperature values at irradiance of $1000 \mathrm{~W} / \mathrm{m}^{2}$ 


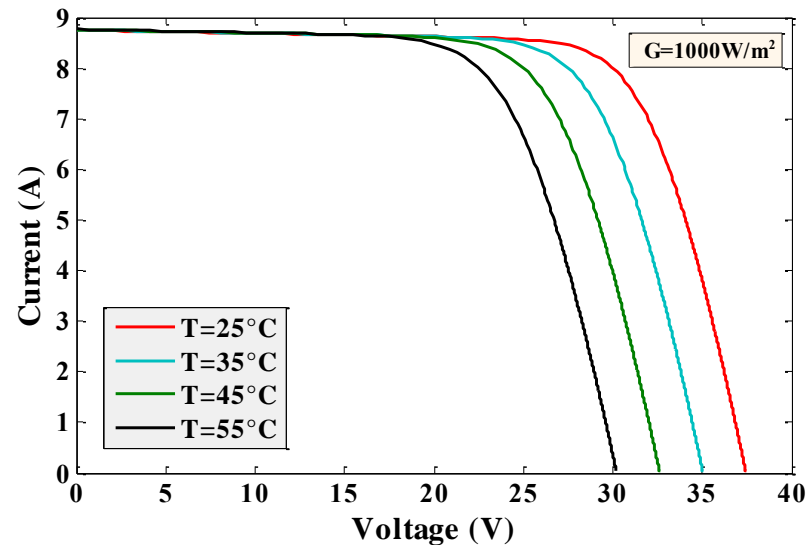

Figure.8 I-V characteristics of a PV module for various temperature values at irradiance of $1000 \mathrm{~W} / \mathrm{m}^{2}$

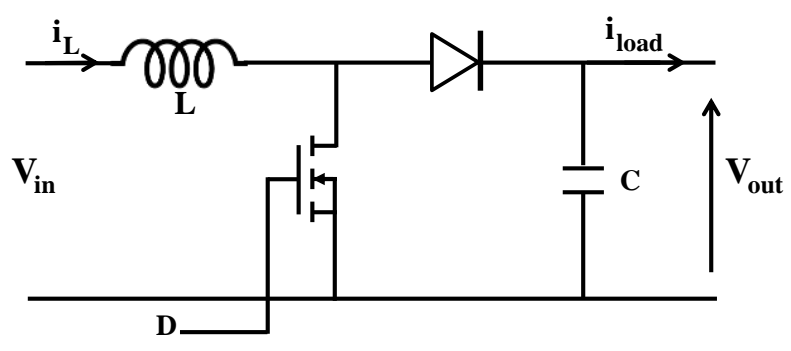

Figure.9 Equivalent boost converter circuit

Figs. 5 and 6 show the characteristics P-V and I$\mathrm{V}$ of the PV panel at a constant temperature $\left(25^{\circ} \mathrm{C}\right)$ for various solar irradiation levels $\left(1000 \mathrm{~W} / \mathrm{m}^{2}\right.$ to $200 \mathrm{~W} / \mathrm{m}^{2}$ ), it is noted that when the solar irradiation increase, the output power and current of the PV module increase.

Figs. 7 and 8 show the characteristics P-V and I$\mathrm{V}$ of the PV panel at a fixed solar irradiation of $1000 \mathrm{~W} / \mathrm{m}^{2}$ for various temperature levels $\left(25^{\circ} \mathrm{C}\right.$ to $55^{\circ} \mathrm{C}$ ), we can observe that the PV output power decreases when the temperature increases. Thus, these characteristics also show that the maximum power point varies according to the variation of temperature and irradiation. So it is necessary to use an MPPT controller to track this point in order to optimize the energy efficiency of our PV system.

\subsection{Modeling of DC/DC boost converter}

In our hybrid system, we propose to integrate a $\mathrm{dc} / \mathrm{dc}$ boost converter [4] [11] between each power generator (PV or Wind) and the load. The equivalent boost converter circuit [9] is shown in Fig. 9.

This converter allows producing at the output a voltage higher than its input voltage. So, it allows to control and regulate the output voltage and current of the PV or Wind generator in order to track the maximum power point of the system thanks to controlling its power switch by a pulse signal generated by the MPPT controller. The relationship between input and output voltage of the boost converter is expressed by [12]:

$V_{\text {out }}=\frac{V_{\text {in }}}{1-D}$

Where $V_{\text {in }}$ is the input voltage (output voltage of $\mathrm{PV}$ or Wind generator), $V_{\text {out }}$ is the output voltage of the boost converter and $D$ is the duty cycle.

The converter functioning depends on the switch state which can be ON or OFF, if $D=1$ the switch is ON otherwise it is OFF. For this reason, the boost converter can be described in two sets of state equation depends on the duty cycle [9]:

$$
\begin{aligned}
& \frac{d i_{L}}{d t}=\frac{1}{L}\left[V_{\text {in }}-V_{\text {out }}(1-D)\right] \\
& \frac{d V_{\text {out }}}{d t}=\frac{1}{C}\left[i_{L}(1-D)-i_{\text {load }}\right]
\end{aligned}
$$

Where $i_{L}$ is the inductor current and $i_{\text {load }}$ is the load current.

\section{MPPT methods}

In a stand-alone renewable energy system, photovoltaic or wind, the use of MPPT controller is essential to optimize system performance and reduce energy losses. Thanks to an MPPT algorithm, it allows to reach and track the optimal operating point in order to extract the maximum power whatever the weather conditions (solar irradiation, temperature, wind speed) and the electrical load. In the literature, there are different traditional MPPT methods have been developed as: Perturb and Observe (P\&O) [3] [7], Incremental Conductance method (INC) [3] for PV system, Hill Climbing Search (HCS) [4] for Wind system. In this work, we propose the development of an MPPT controller based on the sliding mode nonlinear technique [10] for both PV and Wind systems. So, a simulation and a performance comparative study of the proposed technique and the conventional methods on our system efficiency.

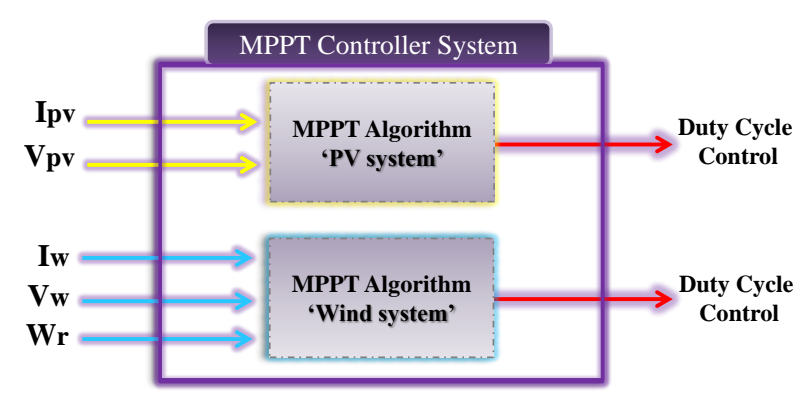

Figure.10 MPPT controller system 
Fig. 10 shows the proposed MPPT controller to optimize our hybrid system which is characterized by five input variables corresponding to: $I_{p v}$ and $V_{p v}$ of the photovoltaic system and $I_{w}, V_{w}$ and $W_{r}$ of the wind system. In the output, the controller generates two duty cycle control signals that have control both $\mathrm{dc} / \mathrm{dc}$ boost converters of the two PV and Wind energy conversion chains.

\subsection{P\&O MPPT for PV system}

In the literature, the Perturb and Observe (P\&O) method [7] is the most used technique to track the maximum power point of a PV system because of its simplicity and ease of implementation. Fig. 11 shows the principle of the $\mathrm{P} \& \mathrm{O}$ algorithm [13] which is based on a small perturbation (incrementing or decrementing) of the PV panel voltage and observing the effect of this perturbation on the output power. If the power increases the following perturbation will continue in that direction, but if the power decreases, the direction of the perturbation must be reversed to ensure proper tracking of the maximum power point (MPP).

\subsection{INC MPPT for PV system}

One of the MPPT techniques also commonly used is the Incremental Conductance (INC) method [3], which allows defining the current operating point compared to the maximum power point and therefore choosing the variation direction of the duty cycle to track the MPP. Its strategy is based on the increase or decrease of the duty cycle according to the comparison sign of the instantaneous conductance $(I / V)$ and the incremental conductance $(\Delta I / \Delta V)$ up to the equality $\Delta I / \Delta V=-I / V$ corresponds to the maximum power point. Fig. 12 shows the flowchart of INC algorithm [13].

\subsection{HCS MPPT for Wind system}

A Hill Climbing Search (HCS) [4] based MPPT controller is more widely used in a wind energy conversion system because of its simplicity of implementation and independence to the wind turbine characteristics $\left(C_{p \text {-opt }}\right.$ and $\left.\lambda_{\text {opt }}\right)$. This algorithm is based on the observation of the perturbation effect of the wind turbine rotor speed on the generator output mechanical power $P_{m}$. If the power increases (case $\Delta P / \Delta \omega>0$ ), the perturbation is continued in the same direction, otherwise (case $\Delta P / \Delta \omega<0)$ the direction of the perturbation must be reversed and this strategy is repeated until the maximum power point of the system is found (case
$\Delta P / \Delta \omega=0$ ). Fig. 13 shows the flowchart of HCS algorithm.

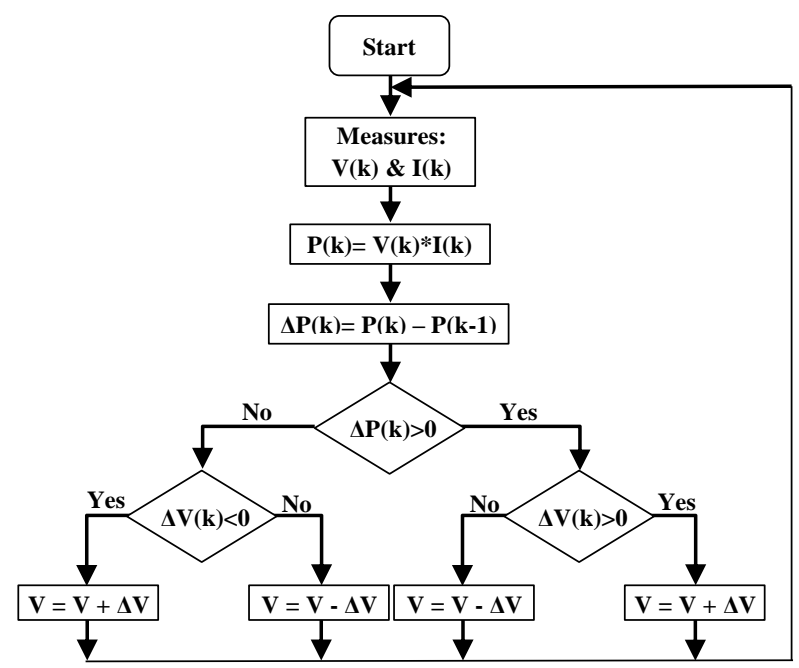

Figure.11 Perturb and observe method flowchart

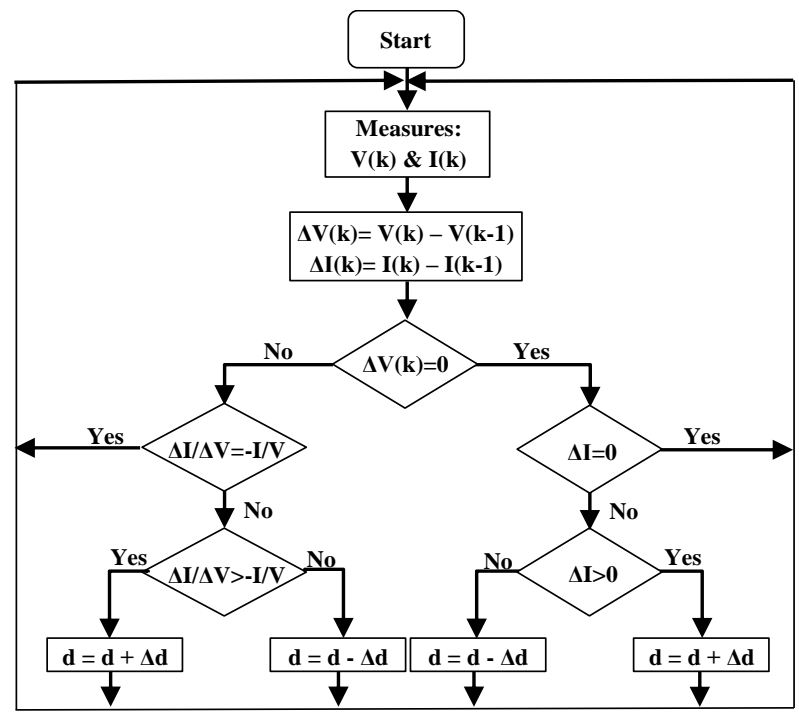

Figure.12 Incremental conductance method flowchart

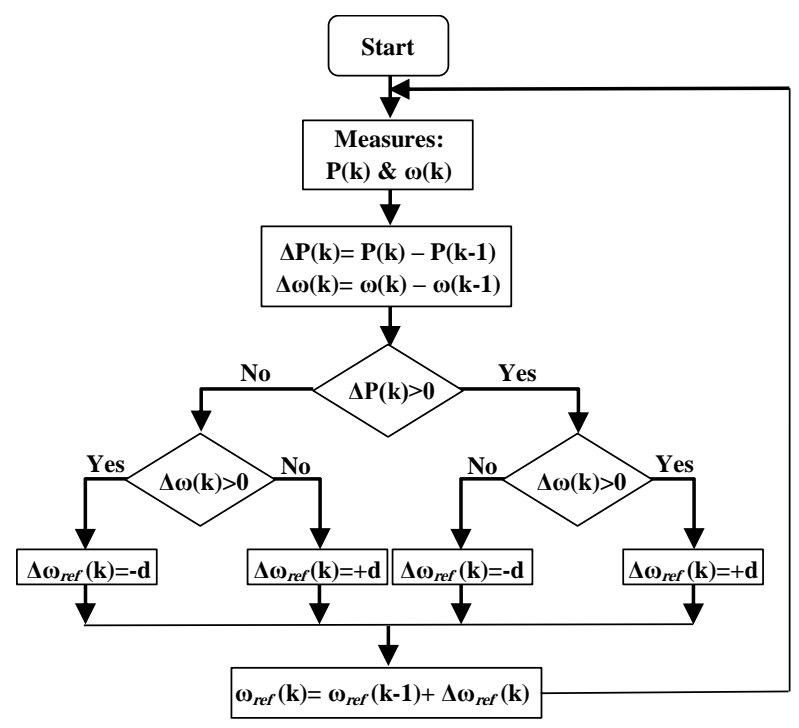

Figure.13 Hill climbing search method flowchart 


\subsection{Robust sliding mode control (RSMC)}

One of the most used nonlinear control techniques to improve the PV and Wind energy systems performance is the sliding mode control (SMC) [7] [14] [15] thanks to its simplicity, robustness and high precision compared to other classical techniques. SMC algorithm allows track the system maximum power point by following twostep [10], the first consists to converge the system to a predefined surface called sliding surface, and the second step is to force the system to stay on that surface and lead it to its optimal power point according to a predefined control law named an equivalent control. However, in an MPPT control based on the sliding mode control, it is necessary to define a sliding surface and an equivalent control.

In this work, our aim is to develop an MPPT controller based on a robust sliding mode control to improve our hybrid system efficiency regardless of weather conditions. For that, we have proposed two algorithms to control both $\mathrm{dc} / \mathrm{dc}$ boost converters for the two solar and wind energy conversion chains. In the following part, we will treat these methods in detail.

\subsubsection{Proposed RSMC algorithm for PV system}

As shown in Fig. 14, this control is based on the combination of $\mathrm{P} \& \mathrm{O}$ and SMC algorithms. $\mathrm{P} \& \mathrm{O}$ technique enables to calculate the reference voltage which can be used afterward in the calculation of sliding surface and equivalent control and consequently generate an adequate control signal to properly optimize the PV generator energy efficiency.

According to the analysis of $\mathrm{P}(\mathrm{V})$ photovoltaic panel characteristic curve and in order to reach the maximum power point corresponds to $d P_{p v} / d V_{p v}=0$ whatever the system operating point position, the sliding surface $S$ can be defined as the following [3]:

$S=\frac{d P_{p v}}{d V_{p v}}=I_{p v}+V_{p v} \cdot \frac{d I_{p v}}{d V_{p v}}=0$

To improve this choice of the sliding surface, we propose to use the reference voltage $V_{\text {ref }}$ defined by the $\mathrm{P} \& \mathrm{O}$ algorithm to calculate a new sliding surface, which can be expressed by:

$S=\frac{d P}{d V}=\frac{P_{p v}-P_{r e f}}{V_{p v}-V_{r e f}}=0$

With: $P_{r e f}=I_{p v} . V_{\text {ref }}$

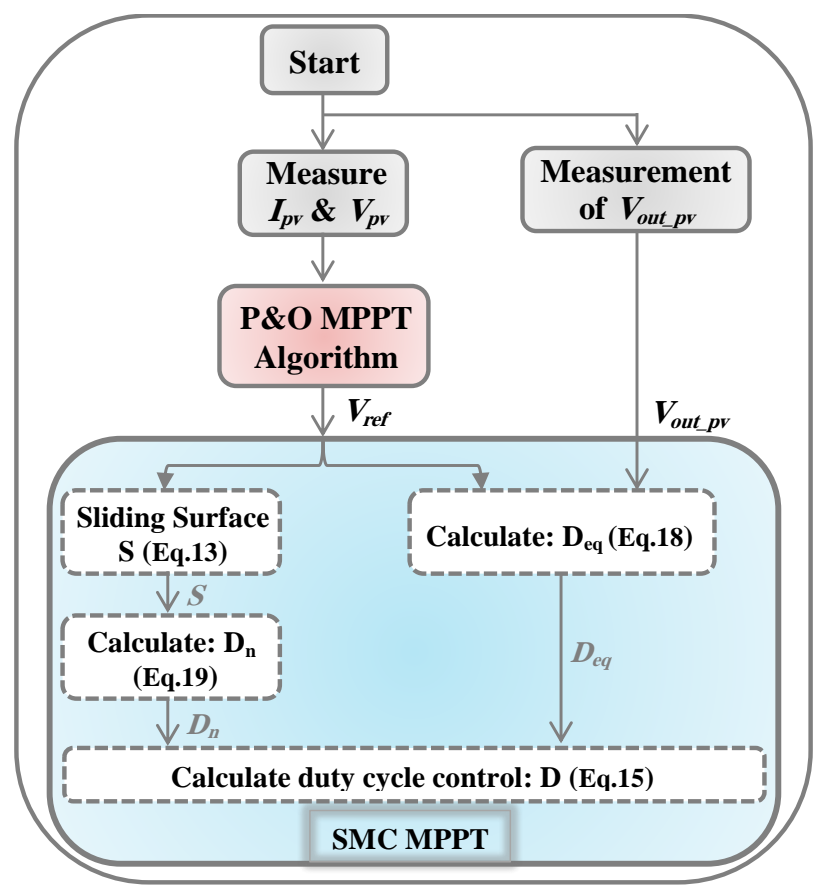

Figure.14 RSMC MPPT method flowchart for PV system

This sliding surface allows us to define the boost converter duty cycle of $\mathrm{PV}$ system which is expressed by [10]:

$D_{k+1}=\left\{\begin{array}{lll}D_{k}-\Delta D, \text { if } & S<0 \\ D_{k}+\Delta D, \text { if } & S>0\end{array}\right.$

And the real control signal is defined by:

$D=\left\{\begin{array}{lr}0 & \text { for } D_{e q}+D_{n} \leq 0 \\ D_{e q}+D_{n} & \text { for } 0<D_{e q}+D_{n}<1(15) \\ 1 & \text { for } D_{e q}+D_{n} \geq 0\end{array}\right.$

Where $D_{e q}$ is the equivalent control and $D_{n}$ represents the discrete control.

The equivalent control $D_{e q}$ is defined from the following condition:

$\dot{S}=\left[\frac{d S}{d X}\right]^{T} \dot{X}=0$

With: $\quad \dot{X}=\frac{d i_{p v}}{d t}=f(x)+g(x) \cdot D_{e q}$

From the boost converter equation (10), we can derive the equivalent control expression as follows [7]:

$D_{e q}=-\frac{\left[\frac{d S}{d X}\right]^{T} \cdot f(x)}{\left[\frac{d S}{d X}\right]^{T} \cdot g(x)}=1-\frac{V_{p v}}{V_{o u t_{-} p v}}$

And to define a good equivalent control, better optimize the system response time and consequently 
improve the tracking of the maximum power point, we proposed to calculate the latter using the same reference voltage predefined by the $\mathrm{P} \& \mathrm{O}$ algorithm. So the equivalent control expression became:

$D_{e q}=1-\frac{V_{\text {ref }}}{V_{\text {out_pv }}}$

Finally, the discrete control $D_{n}$ is chosen as [9]:

$D_{n}=K \cdot \operatorname{Sat}(S)$

With:

$\operatorname{Sat}(S)= \begin{cases}\frac{S}{\varepsilon} & , \text { if }|S|<\varepsilon \\ \operatorname{Sign}(S), & \text { Otherwise }\end{cases}$

Where $K$ is a positive constant and $\varepsilon$ is the boundary layer thickness.

\subsubsection{Proposed RSMC algorithm for Wind system}

As shown in Fig. 15, this command is based initially on the calculation of the reference current based on the knowledge of the wind turbine characteristics and the calculation of the optimal power using Eqs. (23), (24), and (25) [16]. Then we use this reference current to calculate the sliding surface and the equivalent control in order to conclude a better control signal to properly reach and follow the wind system maximum power point.

The proposed sliding surface is as follows:

$S=I_{w_{-} o p t}-I_{w}$

Where $I_{w-o p t}$ is the reference current defined by [16]:

$I_{w_{-} o p t}=\frac{P_{m . o p t}}{V_{w}}$

With:

$P_{m . o p t}=\frac{1}{2} \rho \pi R^{2} C_{\text {p.opt }} V_{\text {wind }}^{3}=K_{\text {opt }} \cdot \omega_{\text {r.opt }}^{3}(23)$

$V_{\text {wind }}=\frac{\omega_{\text {r.opt }} R}{\lambda_{\text {opt }}}$

$K_{\text {opt }}=\frac{1}{2} \cdot \frac{\rho \cdot \pi \cdot R^{5} \cdot C_{p . o p t}}{\lambda_{o p t}^{3}}$

This sliding surface allows us to define the boost converter duty cycle of wind system which is expressed by:

$D_{k+1}=\left\{\begin{array}{lll}D_{k}-\Delta D, \text { if } & S<0 \\ D_{k}+\Delta D, \text { if } & S>0\end{array}\right.$

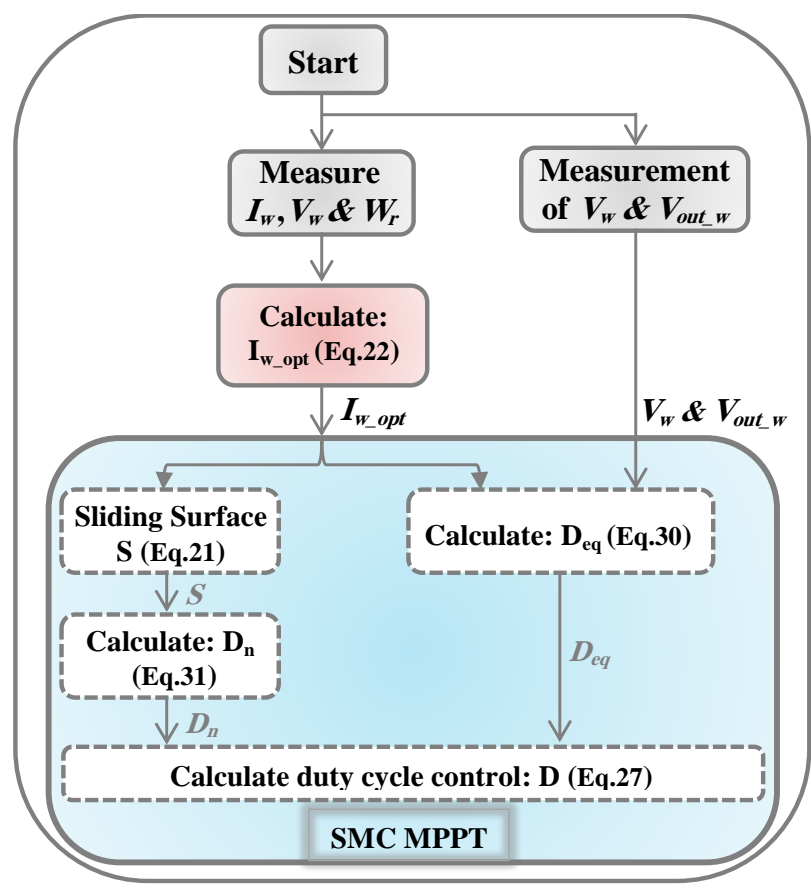

Figure.15 RSMC MPPT method flowchart for wind system

The real control signal is defined by:

$D=\left\{\begin{array}{lr}0 & \text { for } D_{e q}+D_{n} \leq 0 \\ D_{e q}+D_{n} & \text { for } 0<D_{e q}+D_{n}<1(27) \\ 1 & \text { for } D_{e q}+D_{n} \geq 0\end{array}\right.$

The equivalent control $D_{e q}$ is defined from the following condition:

$\dot{S}=\frac{d S}{d t}=\frac{d I_{w_{-} o p t}}{d t}-\frac{d I_{w}}{d t}=0$

From the boost converter equation (10) we have:

$\frac{d I_{w}}{d t}=\frac{d i_{L}}{d t}=\frac{1}{L}\left[V_{w}-V_{\text {out_w }}\left(1-D_{e q}\right)\right]$

So, we can derive the equivalent control expression as the following:

$D_{\text {eq }}=\frac{L}{V_{\text {out } \_}}\left(\frac{d I_{w_{\_} o p t}}{d t}\right)+\left(1-\frac{V_{w}}{V_{\text {out_w }}}\right)$

Finally, the discrete control $D_{n}$ is [15]:

$D_{n}=K \cdot \operatorname{Sat}(S)$

With:

$\operatorname{Sat}(S)= \begin{cases}\frac{S}{\varepsilon} & , \text { if }|S|<\varepsilon \\ \operatorname{Sign}(S), & \text { Otherwise }\end{cases}$

Where $K$ is a positive constant and $\varepsilon$ is the boundary layer thickness. 


\section{Simulation results and discussion}

In this work, and in order to study and analyze the performance of our proposed PV/Wind hybrid energy system, a detailed system simulation was carried out using the Matlab/Simulink software, based on the modeling of different system elements presented previously. Also, an MPPT controller based on new robust approaches has been developed to optimize both PV and Wind energy sources, which have been simulated, evaluated and compared with other traditional algorithms, and in order to verify and validate the proposed techniques robustness, the simulations are realized under variable climatic conditions. These MPPT techniques are: Perturb and Observe (P\&O), Incremental Conductance (INC) and the proposed robust sliding mode control (RSMC) for PV system. Hill Climbing Search (HCS) and the proposed robust sliding mode control (RSMC) for Wind system.

Figs. 16 and 17 show respectively the simulation results corresponding to PV system output power and voltage with a change of solar irradiation $\left(1000 \mathrm{~W} / \mathrm{m}^{2}\right.$ to $800 \mathrm{~W} / \mathrm{m}^{2}, 800 \mathrm{~W} / \mathrm{m}^{2}$ to $600 \mathrm{~W} / \mathrm{m}^{2}$ and $600 \mathrm{~W} / \mathrm{m}^{2}$ to $1000 \mathrm{~W} / \mathrm{m}^{2}$, respectively) and at a constant temperature of $25^{\circ} \mathrm{C}$.

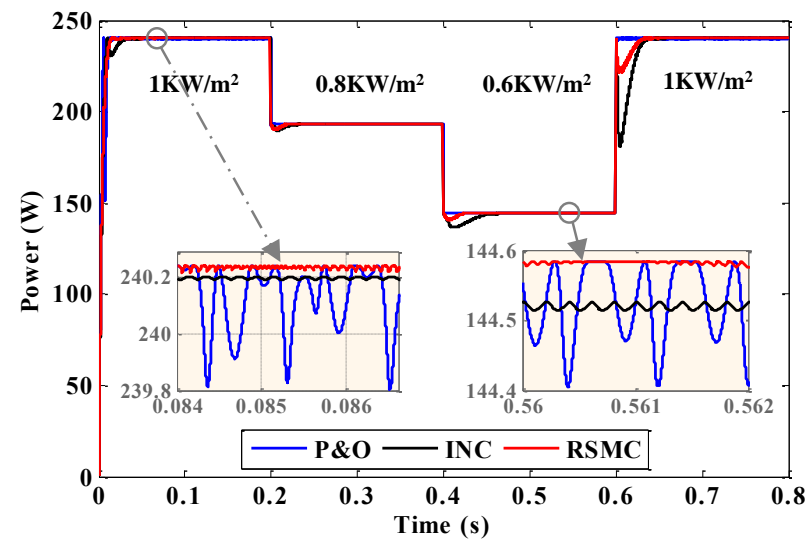

Figure.16 PV generator output power under varying irradiation levels

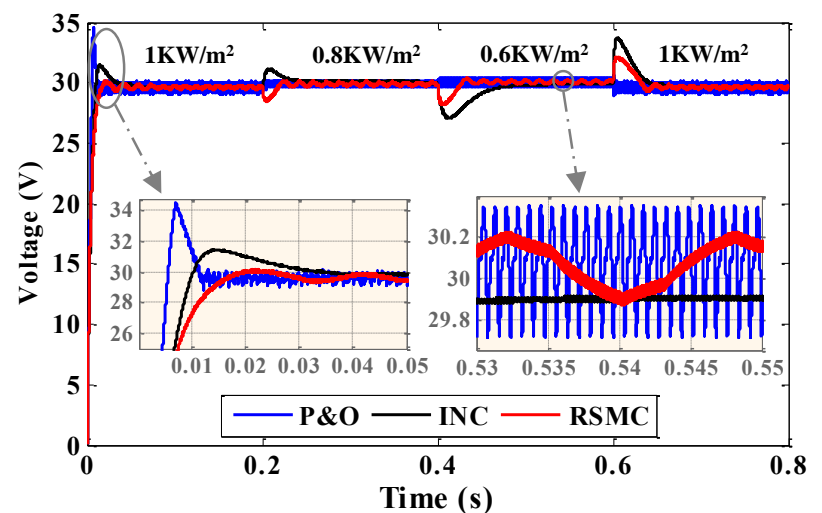

Figure.17 PV generator output voltage under varying irradiation levels

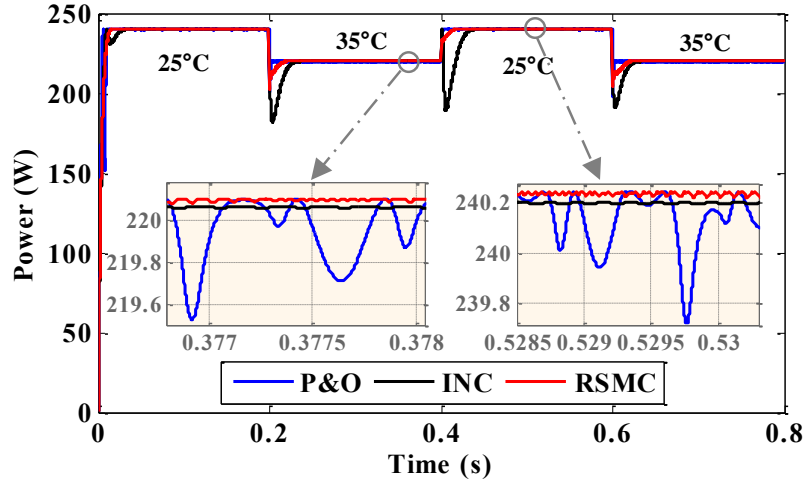

Figure.18 PV generator output power under varying temperature levels

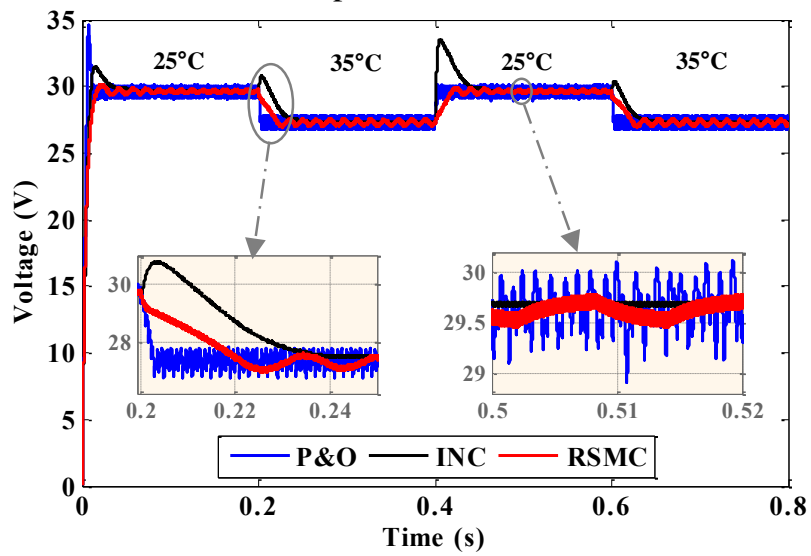

Figure.19 PV generator output voltage under varying temperature levels

Figs. 18 and 19 show respectively the simulation results corresponding to PV system output power and voltage with variation of the temperature value $\left(25^{\circ} \mathrm{C}\right.$ to $35^{\circ} \mathrm{C}, 35^{\circ} \mathrm{C}$ to $25^{\circ} \mathrm{C}$ and $25^{\circ} \mathrm{C}$ at $35^{\circ} \mathrm{C}$, respectively) and at a constant solar irradiation value of $1000 \mathrm{~W} / \mathrm{m}^{2}$.

From these results and according to a critical analysis of the different algorithms by: the response time, the system behavior, the oscillations around the maximum power point and the achieve optimal power, we can conclude that, $\mathrm{P} \& \mathrm{O}$ method presents significant oscillations which implies a great loss of energy, also requires more time to achieve the MPP. The algorithm INC imposes a slower response time to achieve a power point less than other methods, thus presents a poor behavior following a change in solar irradiation. For RSMC control, we note well good transient behavior to search system stability at its maximum power point at $t=0.017 \mathrm{~s}$ which reduces power losses compared to the results of [17] and [18] which propose techniques allows to reach the point MPP at $t=0.021$ and $t=0.1$ respectively. And in the permanent regime, we can clearly see that it allows achieving a greater point of MPP with a more stable, more accurate and fewer oscillations tracking compared to other techniques. This is translated by a significant efficiency of $99.24 \%$ compared to $\mathrm{P} \& \mathrm{O}$ 
and INC techniques which present efficiencies about $98.72 \%$ and $98.44 \%$ respectively. It is noted that this efficiency is calculated based on the method used in [17]. For that, we can say that the proposed RSMC approach is a robust and efficient technique, and it has better performances compared to the conventional methods $\mathrm{P} \& \mathrm{O}$ and INC.

Figs. 20 and 21 show the simulation results corresponding respectively to output mechanical power and power coefficient of wind turbine with a wind speed change $(12 \mathrm{~m} / \mathrm{s}$ to $10 \mathrm{~m} / \mathrm{s}$ and $10 \mathrm{~m} / \mathrm{s}$ to $12 \mathrm{~m} / \mathrm{s}$ respectively).

According to the analysis of the results presented in these figures, it is observed that in transient conditions, the RSMC technique makes it possible to achieve the optimum system characteristics, including the maximum mechanical power and the optimal power coefficient $\left(C_{p}=0.48\right)$, more better than the HCS technique with a good response time of $t=0.6 \mathrm{~s}$. And in the permanent regime, the HCS method has more oscillations around the MPP which implies a loss of energy and a high system sensitivity to small variations in the wind speed. On the other hand, the RSMC approach presents less oscillations, more stability and precision, thus a tracking of the MPP point under variable wind speed conditions with a good dynamic response. From an efficiency viewpoint, the proposed technique has an efficiency of $99.47 \%$ compared to the HCS technique which presents only 91.4\%. Comparing these results with that of the paper [19], which is based on a PMSG generator of the same characteristics used in our work and with an MPPT control based on fuzzy logic, we can well observe that the system energy efficiency with our RSMC algorithm is higher than that of [19]. Therefore, and following these simulation results, it can be said that the proposed robust RSMC algorithm has remarkable advantages and performance than the HCS technique.

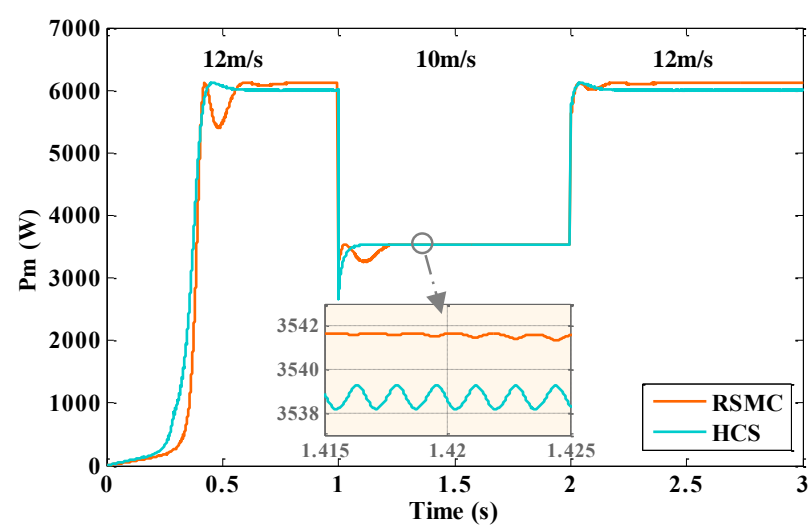

Figure.20 Wind generator output power under varying wind speed levels

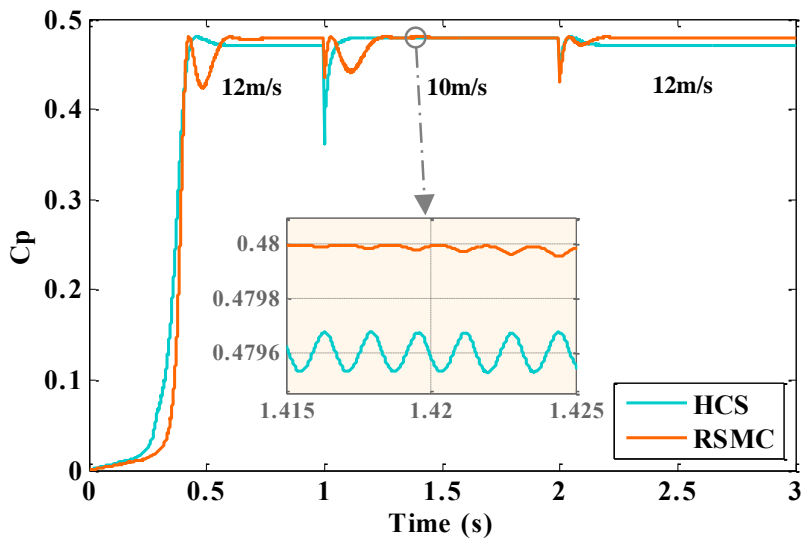

Figure.21 Wind generator power coefficient under varying wind speed levels

\section{Conclusion}

In this work, an MPPT controller based on two robust sliding mode control algorithms (RSMC) was developed to control the both boost converters of a PV/Wind hybrid energy system, with the aim to improve system performance by better tracking the maximum power point (MPP) of the two photovoltaic and wind energy production chains whatever the weather conditions and with significant advantages compared to other methods applied in the literature. These algorithms are based mainly on an improvement of the sliding mode control due to its interesting characteristics. The simulation results confirm that the designed RSMC strategies allow achieving a high energy performance of the two energy sources with a very interesting efficiency. Thanks to a maximum power point tracking with better response times, reduced oscillations and good stability around the MPP. Furthermore, the comparison study of these techniques with other conventional methods, $\mathrm{P} \& \mathrm{O}$ and INC for PV system and HCS for Wind system, shows that the proposed algorithms are more robust against the operating conditions changes, have a high accuracy to reach the optimal MPP point and a significantly higher efficiency.

As a perspective of our work, we thought on the one hand to realize other intelligent hybrid controls based on the fuzzy logic and sliding mode control for both PV and Wind systems, and on the other, the realization of an intelligent strategy for the supervision and management of the energy produced by a stand-alone hybrid energy system that combines a PV generator, a Wind system based of PMSG generator and a storage system (batteries). 


\section{References}

[1] O. Zebraoui and M. Bouzi, "Sizing and Optimization of a Fully Autonomous Hybrid PV-Wind Power System", In: Proc. of the IEEE International Conference on Electrical Sciences and Technologies in Maghreb, pp.227-233, 2016.

[2] S.S. Martin, A. Chebak, A. El Ouafi, and M. Mabrouki, "Modeling and Simulation of Hybrid Power System Integrating Wind, Solar, Biodiesel Energies and Storage Battery", In: Proc. of the IEEE International Renewable and Sustainable Energy Conference, pp.457-463, 2016.

[3] A. Belkaid, J.P. Gaubert, and A. Gherbi, "An Improved Sliding Mode Control for Maximum Power Point Tracking in Photovoltaic Systems", Journal of Control Engineering and Applied Informatics, Vol.18, No.1, pp.86-94, 2016.

[4] J.H. Chen, H.T. Yau, and W. Hung, "Design and Study on Sliding Mode Extremum Seeking Control of the Chaos Embedded Particle Swarm Optimization for Maximum Power Point Tracking in Wind Power Systems", Energies, Vol.7, No.3, pp.1706-1720, 2014.

[5] M.A. Abdourraziq, M. Ouassaid, and M. Maaroufi, "Single-Sensor Based MPPT for Photovoltaic Systems", International Journal of Renewable Energy Research, Vol.6, No.2, pp.570-576, 2016.

[6] D. Shen, P. Khayyer, and A. Izadian, "Sliding Mode Extremum Seeking Control for Maximum Power Point Tracking in Wind System", In: Proc. of the IEEE Power and Energy Conference at Illinois, pp.1-6, 2016.

[7] D. Rekioua, A.Y. Achour, and T. Rekioua, "Tracking Power Photovoltaic System with Sliding Mode Control Strategy", Energy Procedia, Vol. 36, pp. 219-230, 2013.

[8] S. Mayakrishnan, P. Srinivasan, and A. Loganathan, "Integrated Controller for Elimination of Harmonics in PMSG Based WECS Feeding Non Linear Load", International Journal of Intelligent Engineering and Systems, Vol.10, No.3, pp.317-326, 2017.

[9] R. Garraoui, M. Ben Hamed, and L. Sbita, "A Robust Optimization Technique Based on First Order Sliding Mode Approach for Photovoltaic Power Systems", International Journal of Automation and Computing, Vol.12, No.6, pp.620-629, 2015.

[10] T. Laagoubi, M. Bouzi, and M. Benchagra, "Analysis and Comparison of MPPT Nonlinear Controllers for PV System”, In: Proc. of the
IEEE International Renewable and Sustainable Energy Conference, pp.540-544, 2015.

[11] J. Ghazanfari and M. M. Farsangi, "Maximum Power Point Tracking Using Sliding Mode Control for Photovoltaic Array", Iranian Journal of Electrical \& Electronic Engineering, Vol.9, No.3, pp.189-196, 2013.

[12]F. Maissa, O. Barambones, S. Lassad, and A. Fleh, "A Robust MPP Tracker Based on Sliding Mode Control for a Photovoltaic Based Pumping System", International Journal of Automation and Computing, Vol.14, No.4, pp.489-500, 2017.

[13]R.I. Putri, S. Wibowo and M. Rifa'i, "Maximum Power Point Tracking for Photovoltaic Using Incremental Conductance Method", Energy Procedia, Vol.68, pp.22-30, 2015.

[14]O. Belounis and H. Labar, "Fuzzy Sliding Mode Controller of DFIG for Wind Energy Conversion", International Journal of Intelligent Engineering and Systems, Vol.10, No.2, pp.163-172, 2017.

[15] Y. Soufi, S. Kahla, and M. Bechouat, "Particle Swarm Optimization Based Sliding Mode Control of Variable Speed Wind Energy Conversion System", International Journal of Hydrogen Energy, Vol.41, No.45, pp.2095620963, 2016.

[16] G. Koch, T. Gabbi, G. Henz, R.P. Vieira, and H. Pinheiro, "Sensorless Technique Applied to PMSG of WECS Using Sliding Mode Observer", In: Proc. of the $13^{\text {th }}$ IEEE Brazilian Power Electronics Conference and $1^{\text {st }}$ Southern Power Electronics Conference, pp.1-6, 2015.

[17]L. Bouselham, B. Hajji, and H. Hajji, "Comparative Study of Different MPPT Methods for Photovoltaic System", In: Proc. of the $3^{\text {rd }}$ IEEE International Renewable and Sustainable Energy Conference, pp.1-5, 2015.

[18]M.A. Abdourraziq and M. Maaroufi, "Experimental Verification of the Main MPPT Techniques for Photovoltaic System", International Journal of Power Electronics and Drive Systems, Vol.8, No.1, pp.384-391, 2017.

[19]R. Tiwari and N.R Babu, "Fuzzy Logic based MPPT for Permanent Magnet Synchronous Generator in Wind Energy Conversion System", IFAC-PapersOnligne, Vol.49, No.1, pp.462467, 2016. 